\title{
Структура термоэлектрических пленок высшего силицида марганца на кремнии по данными электронной микроскопии
}

\author{
() А.С. Орехов ${ }^{1,2}$, Т.С. Камилов ${ }^{3}$, Б.В. Ибрагимова ${ }^{3}$, Г.И. Ивакин ${ }^{1}$, В.В. Клечковская ${ }^{1}$ \\ ${ }^{1}$ Институт кристаллографиии им. А.В. Шубникова \\ Федерального научно-исследовательского центра „Кристаллография и фотоника“ \\ Российской академии наук, \\ 119333 Москва, Россия \\ ${ }^{2}$ Национальный исследовательский центр „Курчатовский институт“, \\ 123182 Москва, Россия \\ ${ }^{3}$ Ташкентский государственный технический университет, \\ 100095 Ташкент, Узбекистан \\ E-mail: andrey.orekhov@gmail.com
}

(Получена 12 декабря 2016 г. Принята к печати 19 декабря 2016 г.)

\begin{abstract}
Проведен сравнительный анализ структурных особенностей пленок высшего силицида марганца, выращенных методом диффузионного легирования монокристаллических подложек кремния парами марганца в запаянной ампуле и проточном кварцевом реакторе при постоянной откачке. Методами растровой электронно-ионной микроскопии и высокоразрешающей просвечивающей электронной микроскопии показано, что в откаченной ампуле формируется однофазная текстурированная пленка высшего силицида марганца. Изменение условий роста со стационарных (ампула) на квазистационарные (реактор) приводит к формированию поликристаллических островков высшего силицида марганца с наноразмерными включениями фазы моносилицида марганца.
\end{abstract}

DOI: 10.21883/FTP.2017.06.44547.06

\section{1. Введение}

Тонкие пленки силицидов переходных металлов, в том числе высших силицидов марганца (BCM), уже находят применение в современной микро- и наноэлектронике, оптоэлектронике, микросенсорике и других областях современной техники [1-4]. Показана возможность создания пленочных термобатарей и других термоэлементов на основе ВСМ на кремнии [5]. Однако разработка новых приборов на основе пленок высшего силицида марганца требует детального изучения механизма начальной стадии образования зародышей на подложке и дальнейшего роста пленки в условиях выбранного эксперимента, а также совокупности твердофазных реакций, протекающих в системе $\mathrm{Mn} / \mathrm{Si}$ при повышенных температурах. Экспериментальных данных о химическом и фазовом составе тонких пленок ВСМ крайне мало, а имеющиеся данные довольно противоречивы, что может быть связано с разными методами получения пленок.

Как известно, для бинарной системы $\mathrm{Mn}-\mathrm{Si}$ характерно формирование различных фаз высших силицидов марганца, так называемого ряда фаз Новотного $\mathrm{Mn}_{4} \mathrm{Si}_{7}, \mathrm{Mn}_{11} \mathrm{Si}_{19}, \mathrm{Mn}_{15} \mathrm{Si}_{26}, \mathrm{Mn}_{27} \mathrm{Si}_{47}$ [6-8]. В процессе роста, как монокристаллов, так и пленок ВСМ могут появляться выделения фазы моносилицида марганца, кардинально отличающейся по физическим характеристикам от ВСМ и негативно влияющей на термоэлектрические свойства системы в целом [9-11].

В настоящей работе методами растровой и просвечивающей электронной микроскопии проведен сравнительный анализ микро- и наноструктуры пленок ВСМ, получаемых с помощью диффузионного легирования монокристаллических подложек кремния парами марганца в откачанной кварцевой ампуле и в проточном кварцевом реакторе при постоянной откачке.

\section{2. Материалы и методы}

Формирование пленок ВСМ проходило при температуре подложки $1040^{\circ} \mathrm{C}$ в течение $15-20$ мин с последующим медленным охлаждением до комнатной температуры. Подробное описание метода получения приведено в [12]. Морфология образцов изучалась методом растровой электронной микроскопии на приборе FEI Scios FEG в режимах вторичных и обратно рассеянных электронов. Строение границы раздела пленка-подложка исследовалось методом просвечивающей электронной микроскопии высокого разрешения в микроскопе FEI Titan TEM/STEM 80-300, оборудованном автоэмиссионным катодом Шоттки, а также корректором сферической аберрации объективной линзы для растрового просвечивающего режима. Моделирование расчетных изображений проводилось в программном пакете JEMS (Java Electron Microscopy Simulation) [13].

\section{3. Экспериментальные результаты}

Исследование микроструктуры пленок, выращенных указанными выше методами, показало, что при стационарных условиях осаждения паров марганца на подложку кремния в откачанной ампуле формируется 


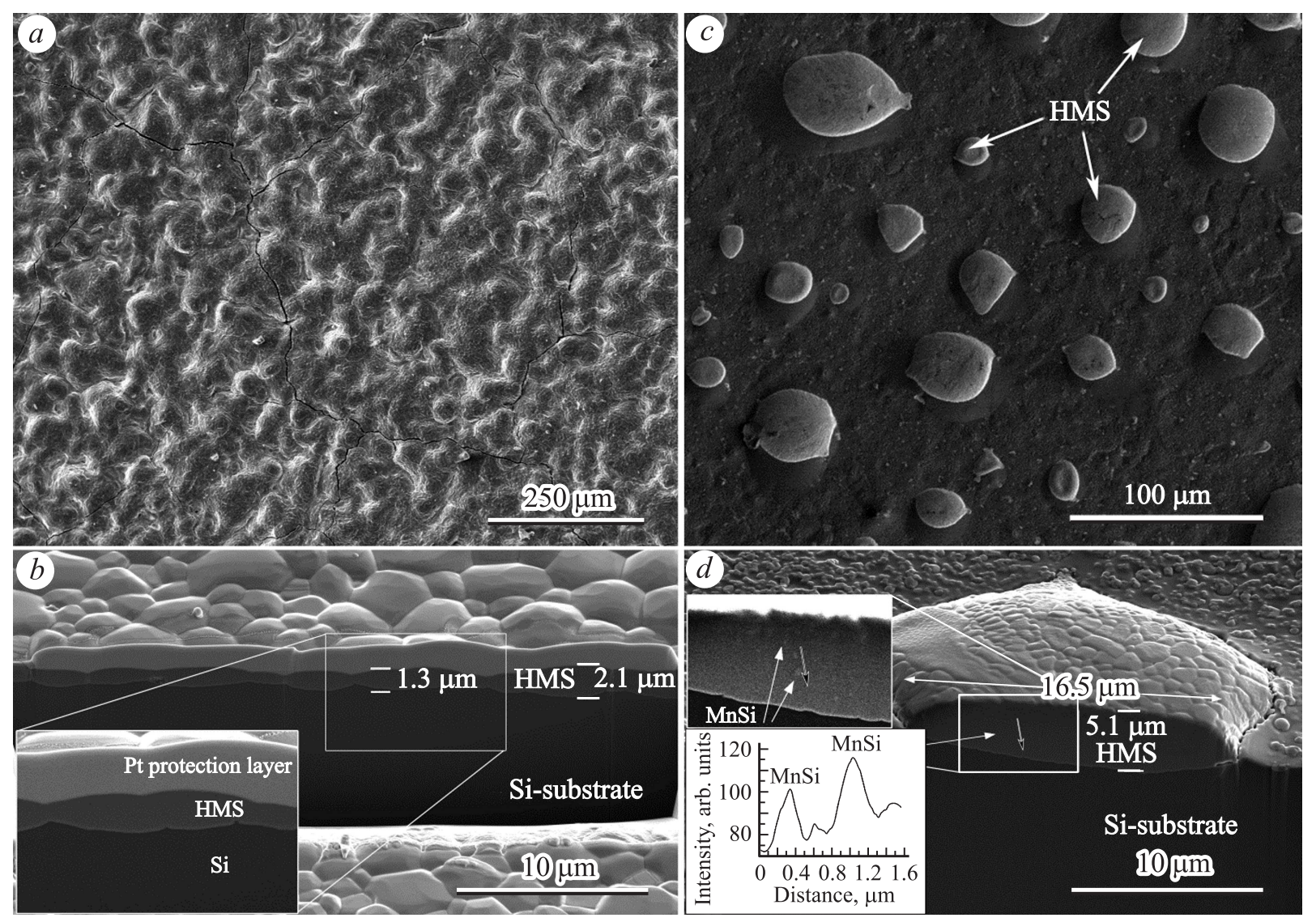

Рис. 1. РЭМ-изображения морфологии пленки ВСМ, полученной в откачанной ампуле $(a, b)$ и в проточном реакторе при постоянной откачке $(c, d)$. На вставке $d$ приведено увеличенное изображение среза островка ВСМ и профиль распределения относительной интенсивности РЭМ изображения (построенный вдоль черной линии) с максимумами, соответствующими наноразмерным выделениям MnSi.

сплошная поликристаллическая пленка высшего силицида марганца $\mathrm{Mn}_{4} \mathrm{Si}_{7}$ (рис. 1,a). С помощью анализа поперечного среза была определена толщина пленки, которая составляет от 1 до 2 мкм (рис. $1, b$ ). Перед приготовлением среза на поверхность пленки локально был нанесен защитный слой платины. Микроструктура образцов, полученных при квазистационарных условиях осаждения марганца в реакторе, характеризуется наличием равномерно расположенных на поверхности подложки кремния больших островков силицида марганца диаметром от 9 до 70 мкм (рис. 1,c). Расстояние между островками силицида марганца составляет 20-100 мкм. На изображении поперечного среза одного из островков наблюдаются более светлые по контрасту наноразмерные выделения диаметром 200 нм и менее (рис. 1,d). На вставке рис. $1, d$ приведено увеличенное изображение выделений и профиль распределения относительной интенсивности РЭМ изображения, построенный через них. Анализ контраста изображений и морфологии выделений показал, что эти наночастицы могут принадлежать кубической фазе моносилицида марганца $\mathrm{MnSi}$.

Сравнительный анализ поперечных срезов островков высшего силицида марганца, полученных двумя мето- дами, был проведен на наноуровне методом просвечивающей электронной микроскопии высокого разрешения. На рис. 2, $а$ приведено растровое просвечивающее электронно-микроскопическое изображение поперечного среза островков ВСМ, выращенных в откачанной ампуле. Как известно [14], контраст на изображениях, полученных с помощью высокоуглового кольцевого темнопольного детектора HAADF, используемого в данном режиме, обратно пропорционален атомному номеру элемента, и с его помощью формируются изображения с так называемым Z-контрастом. Изображения поперечного среза зерен ВСМ имеют равномерный контраст и не содержат каких-либо нанокристаллических выделений. Таким образом, можно сделать предположение, что пленки ВСМ, полученные в ампуле, однофазны.

Детальный анализ структуры границы раздела зерен ВСМ и подложки, выполненный методом высокоразрешающей просвечивающей электронной микроскопии (ВРЭМ), позволяет сделать вывод об отсутствии переходного или промежуточного слоя (рис. 2, $b$ ). Уточнение структуры островка ВСМ и подложки было проведено методом компьютерного моделирования расчетных ВРЭМ-изображений. На вставке А1 и А2 


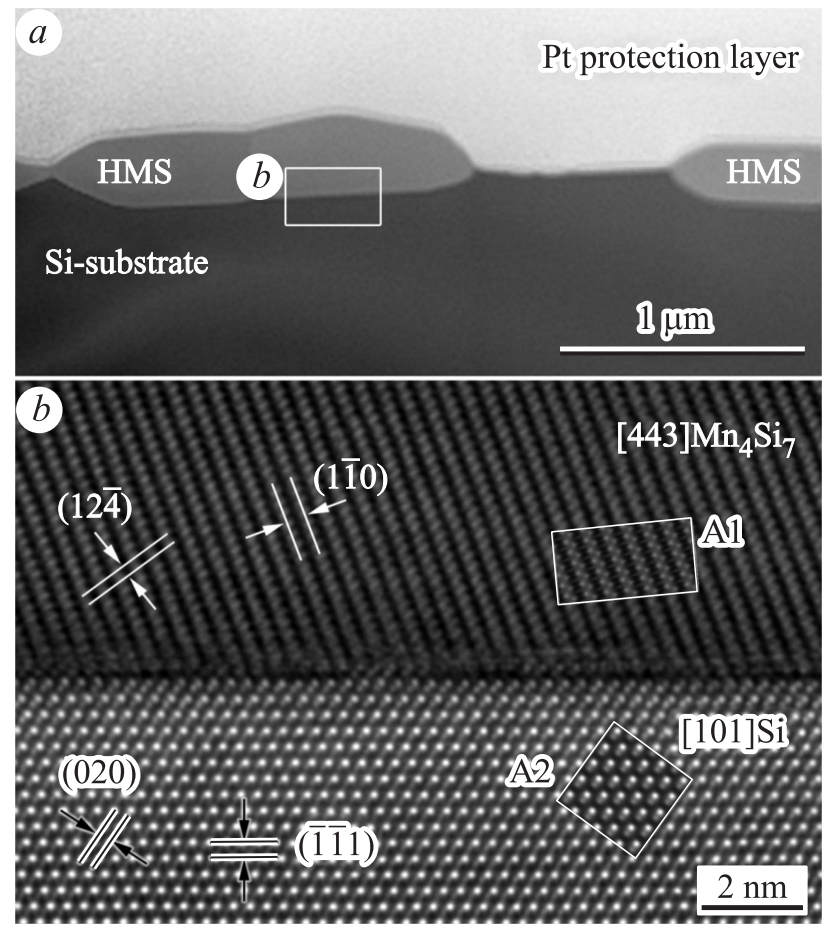

Рис. 2. Растровое просвечивающее электронно-микроскопическое изображение поперечного среза островков ВСМ, выращенных в откачанной ампуле $(a)$. Высокоразрешающее просвечивающее электронно-микроскопическое изображение границы раздела островка ВСМ и подложки кремния $(b)$. На вставках А1 и А2 приведены расчетные ВРЭМ изображения, соответствующие ориентации кристалла ВСМ направлением [443] $\mathrm{Mn}_{4} \mathrm{Si}_{7}$ и подложки кремния направлением [101] $\mathrm{Si}$ нормально к плоскости рисунка.

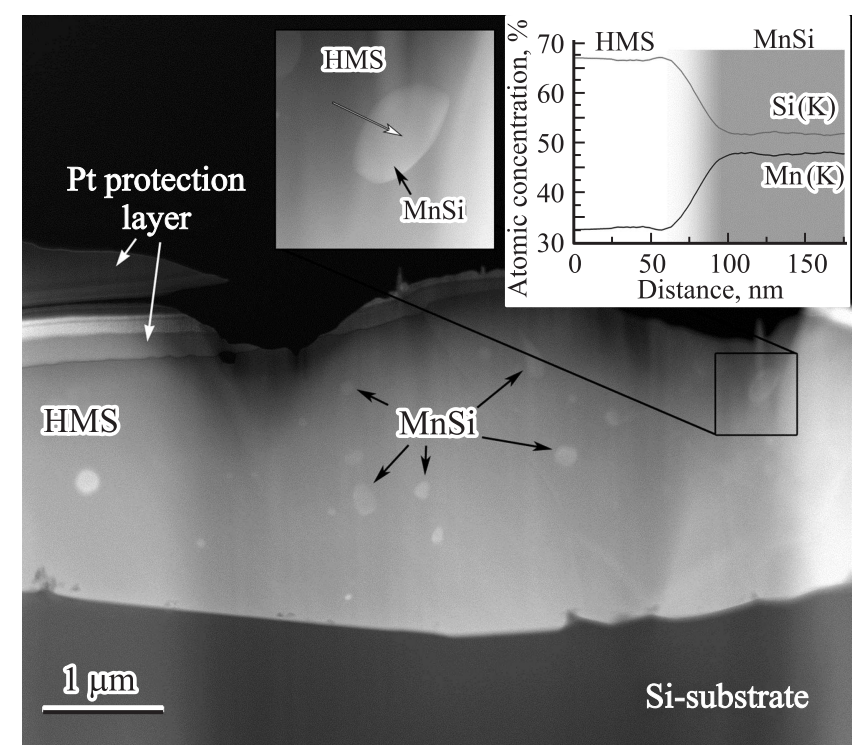

Рис. 3. Изображение поперечного среза островка ВСМ на подложке кремния, выращенного в реакторе при постоянной откачке. Светлые округлые выделения соответствуют фазе кубического моносилицида марганца, что подтверждается полученным профилем распределения концентрации $\mathrm{Mn}$ и $\mathrm{Si}$, приведенного на вставке. рис. 2, $b$ приведены расчетные изображения для фазы $\mathrm{BCM} \mathrm{Mn}_{4} \mathrm{Si}_{7}$ и подложки $\mathrm{Si}$, ориентированных вдоль направлений [443] $\mathrm{Mn}_{4} \mathrm{Si}_{7}$ и [101] $\mathrm{Si}$ перпендикулярно к плоскости рисунка. Хорошее совпадение расчетного и экспериментальных ВРЭМ-изображений подтверждает правильность установленной фазы ВСМ $\mathrm{Mn}_{4} \mathrm{Si}_{7}$. Более подробный анализ структуры границы раздела пленка ВСМ/подложка приведен в работе [15].

Анализ поперечного среза островка ВСМ, выращенного в реакторе, показал наличие наночастиц моносилицида марганца $\mathrm{MnSi}$ размером от 70 до $300 \mathrm{Hм}$ (рис. 3). Фазовый состав выделений проводился по данным электронной дифракции и рентгеновским энергодисперсионным спектрам. Профиль распределения относительной концентрации марганца и кремния, построенный поперек границы раздела наглядно показывает различие в химическом составе островка ВСМ и выделения (см. вставку на рис. 3). Микроструктура островков ВСМ соответствует поликристаллу с размером зерен до единиц микрон.

Образование наноразмерных округлых выделений моносилицида марганца, выявленных в островках ВСМ объемом свыше 1000 мкм³ $^{3}$, по-видимому, может быть связано с формированием объемного сростка относительно больших зерен ВСМ, для которых характерно выделение паразитной фазы MnSi.

\section{4. Заключение}

Сравнительный анализ микро- и наноструктуры пленок ВСМ, полученных в откачанной кварцевой ампуле и в проточном реакторе, показал, что изменение от стационарного к квазистационарному способу выращивания приводит к значительному изменению микроструктуры и фазового состава пленок ВСМ. Полученные результаты в очередной раз свидетельствуют о необходимости проведения структурных исследований пленок высшего силицида марганца для оптимизации условий получения образцов и создания термоэлементов на их основе с заданными электрофизическими свойствами.

Работа выполнена при частичной финансовой поддержке стипендии президента РФ молодым ученым и аспирантам № СП-1404.2016.1 с использованием оборудования ЦКП ИК РАН и ресурсного центра зондовой и электронной микроскопии Курчатовского комплекса НБИКС-технологий.

\section{Список литературы}

[1] S.L. Zhang, M. Ostling. Crit. Rev. Solid State Mater. Sci., 28, 1 (2003).

[2] A.L. Schmitt, J.M. Higgins, J.R. Szczech, S. Jin. J. Mater. Chem., 20, 223 (2010).

[3] C.A. Nolph, E. Vescovo, P. Reinke. Appl. Surf. Sci., 255, 7642 (2009).

[4] J.E. Mahan. Thin Sol. Films, 461 (1), 152 (2004). 
[5] Т.С. Камилов, В.В. Клечковская, Б.З. Шарипов, И.В. Эрнст, В.К. Зайцев. Электрические и фотоэлектрические свойства гетерофазных структур на основе кремния $и$ силицидов марганца (Ташкент, MERIYUS, 2014).

[6] U. Gottlieb, A. Sulpice, B. Lambert-Andron, O. Laborde. J. Alloys Comp., 361 (1-2), 13 (2003).

[7] O. Schwomma, A. Preisinger, H. Nowotny, A. Wittmann. Monatsh. Chem., 95 (6), 1527 (1964).

[8] O. Schwomma, H. Nowotny, A. Wittmann. Monatsh. Chem., 94 (4), 681 (1963).

[9] L.M. Levinson. J. Solid State Chem., 6, 126 (1973).

[10] А.С. Орехов, Е.И. Суворова. Кристаллография, 59 (1), 83 (2014). [Eng. version A.S. Orekhov, E.I. Suvorova. Cryst. Rep., 59 (1), 78 (2014)].

[11] Z.M. Wang, Y.D. Wu, Y.J. He. Int J. Mod. Phys. B, 18 (1), 87 (2004).

[12] В.В. Клечковская, Т.С. Камилов, С.И. Адашева, С.С. Худайбердыев, В.И. Муратова. Кристаллография, 39 (5), 894 (1994).

[13] P. Stadelman. JEMS electron microscopy simulation software. http://cime.epfl.ch/reserch/jems

[14] D.B. Williams, C.B. Carter. The transmission electron microscopy. A Textbook for Materials Science (Springer Science \& Business Media, 2009) p. 760.

[15] А.С. Орехов, Т.С. Камилов, А.С. Орехов, Н.А. Архарова, Е.В. Ракова, В.В. Клечковская. Рос. нанотехнологии, 11 (5-6), 46 (2016). [Eng. version A.S. Orekhov, T.S. Kamilov, A.S. Orekhov, N.A. Arkharova, E.V. Rakova, V.V. Klechkovskaya. Nanotech. in Rus., 11 (9-10), 610 (2016)].

Редактор А.Н. Смирнов

\section{Structure of the thermoelectric films of higher manganese silicide on silicon by electron microcopy}

A.S. Orekhov ${ }^{1,2}$, T.S. Kamilov ${ }^{3}$, B.V. Ibragimova ${ }^{3}$, G.I. Ivakin ${ }^{1}$, V.V. Klechkovskaya ${ }^{1}$

${ }^{1}$ Shubnikov Institute of Crystallography of Federal Scientific Research Centre "Crystallography and Photonics" of Russian Academy of Science, 119333 Moscow, Russia

${ }^{2}$ National Research Centre „Kurchatov Institute“, 123182 Moscow, Russia

${ }^{3}$ Tashkent State Technical University, 100095 Tashkent, Uzbekistan

Abstract The comparative analysis of structural features was carried out for higher manganese silicide films grown by reactive deposition of evaporated manganese onto silicon substrate in a sealed quartz ampule and in a quartz reactor with a continuous pumping. Scanning electron-ion microscopy and high-resolution transmission electron microscopy shows that at evacuated ampoule the textured single-phase film of higher manganese silicide is formed. Changes of the growth conditions from fixed (ampoule) to the quasi-stationary (reactor) leads to formation of the polycrystalline higher manganese silicide islands with nanoscale inclusions of manganese monosilicide phase. 